\title{
Improvement in cardiovascular and renal outcomes in type 2 diabetes: effect of glycemic control, not drugs
}

Keywords: type 2 diabetes, hemoglobin, cardiovascular, glycemic control, UKPDS

Abbreviations: HbAlc, hemoglobin; CV, cardiovascular; UKPDS, United Kingdom diabetes study; SGLT2, sodium-glucose cotransporter-2

Authors of a recent Systematic Review and Network Metaanalysis made it clear that the comparisons for glycemic efficacy, safety and other outcomes are best demonstrated on administration in drug naive subjects with type 2 diabetes. ${ }^{1}$ The objective of this perspective is to examine the design, the results and conclusion of these studies specifically because of them sponsored and funded by pharmaceutical manufacturers. I believe that comparisons can be deemed valid only if glycemic efficacy is assessed as percent fall from the baseline glycated hemoglobin (HbA1c) in subjects administered the equivalent or maximum daily doses of drugs as approved by regulatory as demonstrated previously. ${ }^{2} \mathrm{~A}$ fall of $\mathrm{HbA} 1 \mathrm{c}$ points may be acceptable only if the HbAlc levels prior to administration of individual agents are not significantly different and the daily dose of agents are equivalent e.g. Maximum recommended daily dose. Finally, therapeutic interventions of other accompanying disorders must be identical to establish the validity of these studies. Unfortunately, most of the comparative trials especially between newer agents and the old established drugs e.g. Metformin and Sulfonylureas have been conducted with the maximum recommended daily dose of the newer drugs with minimal to about half the maximum daily dose of the older drug e.g. Linagliptin $5 \mathrm{mg}$ vs Glimepiride 1-4 mg. ${ }^{3,4}$ These trials therefore are less than valid and are not reliable. Finally, this proposed design is appropriate for assessments of all endpoints, e.g. glycemic efficacy, hypoglycemia, body weights, side effects, costs as well as other long term outcomes including cardiovascular (CV) events.

In documented clinical of trials, the benefits in cardiovascular and renal outcomes may be attributed to improvement in glycemic control as was well documented in United Kingdom Diabetes Study (UKPDS). ${ }^{5-7}$ Percentage improvement in $\mathrm{CV}$ and renal outcomes for the fall in HbAlc in these trials matched almost identically to that observed in UKPDS. e.g. $20 \%$ decline in overall mortality and 14-16 $\%$ lowering in myocardial infarctions and decline of almost $40 \%$ in renal complications for each 1 point drop in HbAlc. ${ }^{5-7}$ Investigators of LEADER Trial using Liraglutide conceded recently that lowering of HbAlc was the major contributor to improvement in CV outcomes. ${ }^{8}$ Similarly, investigators of CANVAS program and CREDENCE TRIAL recently reported lack of reduction in events of myocardial infarction. ${ }^{9}$ Thus, the finding of lowering of $\mathrm{CV}$ events with lowering of $\mathrm{HbA} 1 \mathrm{c}$ is consistent with several studies showing increased adverse CV out comes with rising $\mathrm{HbA} 1 \mathrm{c}$ in a population irrespective of the presence of diabetes. ${ }^{10-15}$ In fact, recent reports documented 18-23\% increased occurrence of myocardial infarction for each point $\mathrm{HbA} 1 \mathrm{c}$ rise over 6.5-7 \%, an almost identical finding in UKPDS. ${ }^{10-15}$ Moreover, none of these trials have been examined for 'Legacy effect' documented in UKPDS. ${ }^{16,17}$ Finally, it is apparent that some of these trials may
Volume 8 Issue 2 - 202I

\author{
Udaya M Kabadi \\ Chief, Endocrine Section, Broadlawns Medical Center, Adjunct \\ Professor of Medicine, University of lowa, USA \\ Correspondence: Udaya M Kabadi MD, FACP, FRCP (C), \\ FACE, Chief, Endocrine Section, Broadlawns Medical Center, \\ Adjunct Professor of Medicine, University of lowa, lowa City, \\ lowa, Des Moines University, Des Moines, lowa I80I, Hickman \\ Road, Des Moines, lowa 503 |4, USA, Tel + I515282304I, \\ Email ukabadi@gmail.com
}

Received: June 21, 202I | Published: September 24, 202 I

have exaggerated the benefits. ${ }^{18,19}$ Furthermore, many of the trials with newer agents touting cardiovascular and renal benefits are ill designed with several limitations as noted in recent reports. ${ }^{18,19}$ Interpretations of results of Multinational trials are especially worrisome because of different pathophysiologic mechanisms among individual nations due diverse ethnicities, body weights, life styles, dietary patterns etc. Moreover, lack of uniformity in therapeutic guidelines in management of associated chronic disorders among individual nations allowed in multinational trials is further likely to influence the results as well. Finally, the validity and reliability of the conclusions derived from these trials may be biased since they are sponsored and funded by pharmaceutical manufacturers interested in promoting their drugs. Therefore, regulatory government agencies should mandate that the results from pharmaceutical company sponsored and funded trials be duplicated and confirmed by independent entities, ${ }^{5-7,20-23}$ before awarding a tacit approval for prescribing by practicing providers. Improvement in congestive heart failure following administration of Sodium-glucose Cotransporter-2 (SGLT2) Inhibitors may be attributed to osmotic diuresis induced by glycosuria. ${ }^{1}$ The role of glycosuria in inducing remission of congestive heart failure was evident in another study which documented the same outcome with lapse of glycemic control with resultant glycosuria. ${ }^{24}$ However, serious consequences of glycosuria including sepsis due to urinary tract bacterial infections, genitourinary mycotic infections, Fourniet's gangrene, as well as several other adverse effects along with prohibitive costs render SGLT2 inhibitors distinctly less favorable and acceptable when compared with older more effective and less expensive agents e.g. Furosemide, bumetinide, thiazides and other diuretics with proven long term record over several years. ${ }^{23-25}$

In conclusion, comparative clinical trials between newer and older drugs in assessing safety and efficacy in management of hyperglycemia are less than valid because of lack of administration of equivalent daily doses in drug naive subjects. Moreover, the data regarding impact of new drugs on cardiovascular and renal outcomes is overstated as these trials demonstrate no additional improvement beyond that achieved by improvement in glycemic control. Finally 
the results and conclusions based on clinical trials sponsored by manufacturers of the drugs require confirmation by studies conducted by independent entities such as UKPDS.

\section{Acknowledgments}

None.

\section{Conflicts of interest}

The author declares that there is no conflict of interest.

\section{Funding}

None.

\section{References}

1. Apostolos Tsapas, Ioannis Avgerinos, Thomas Karagiannis, et al. Comparative effectiveness of glucose-lowering drugs for type 2 diabetes. a systematic review and network meta-analysis. Ann Intern Med. 2020;173(4):278-286.

2. Kabadi UM. Cost-effective management of hyperglycemia in patients with type 2 diabetes using oral agents. Manag Care. 2004;13(7):48-59.

3. Julio Rosenstock, Steven E Kahn, Odd Erik Johansen, et al. Effect of linagliptin vs glimepiride on major adverse cardiovascular outcomes in patients with type 2 diabetes: the CAROLINA randomized clinical trial. JAMA. 2019;322(12):1155-1166.

4. Intensive blood-glucose control with sulphonylureas or insulin compared with conventional treatment and risk of complications in patients with type 2 diabetes (UKPDS 33). UK Prospective Diabetes Study (UKPDS) Group. Lancet. 1998;352(9131):837-853.

5. Effect of intensive blood-glucose control with metformin on complications in overweight patients with type 2 diabetes (UKPDS 34). UK Prospective Diabetes Study (UKPDS) Group. Lancet. 1998;352(9131):854-865.

6. Kabadi UM. United Kingdom prospective diabetes study: a different perspective. Endocri Pract. 2002;8(1):61.

7. Buse JB, Bain SC, Mann JFE, et al. Cardiovascular risk reduction with liraglutide: an exploratory mediation analysis of the leader trial. Diabetes Care. 2020;43(7):1546-1552.

8. Jie Yu, Jingwei Li. Phillip J Leaver, et al. Effects of canagliflozin on myocardial infarction: a post hoc analysis of the CANVAS program and CREDENCE trial. Cardiovasc Res. 2021:cvab128.

9. Cavero-Redondo I, Peleteiro B, Álvarez-Bueno C, et al. Glycated haemoglobin A1c as a risk factor of cardiovascular outcomes and all-cause mortality in diabetic and non-diabetic populations: a systematic review and meta-analysis. BMJ Open. 2017;7(7):e015949.

10. Danielle C Colayco, Fang Niu, Jeffrey S McCombs, et al. A1C and cardiovascular outcomes in type 2 diabetes: a nested case-control study. Diabetes Care. 2011;34(1):77-83
11. D Giugliano, P Chiodini, MI Maiorino, et al. Cardiovascular outcome trials and major cardiovascular events: does glucose matter? A systematic review with meta-analysis. J Endocrinol Invest. 2019;42(10):1165-1169.

12. de Jong M, Woodward M, Peters SAE. Diabetes, glycated hemoglobin, and the risk of myocardial infarction in women and men: a prospective cohort study of the UK biobank. Diabetes Care. 2020,43(9):2050-2059.

13. Michael Fralick, Michael Colacci, Ayodele Odutayo, et al. Lowering of hemoglobin A1C and risk of cardiovascular outcomes and allcause mortality, a meta-regression analysis. J Diabetes Complications. 2020;34(11):107704.

14. Eric Yf Wan, Esther Yt Yu, Julie Y Chen, et al. Associations between usual glycated haemoglobin A1c and cardiovascular disease in patients with type 2 diabetes mellitus: a 10-year diabetes cohort study. Diabetes Obes Metab. 2020;22(12):2325-2334.

15. Holman RR, Paul SK, Bethel MA, et al. 10-year follow-up of intensive glucose control in type 2 diabetes. $N$ Engl J Med. 2008;359(15):15771589.

16. Laiteerapong N, Ham SA, Gao Y et al. The legacy effect in type 2 diabetes: impact of early glycemic control on future complications (the diabetes \& aging study). Diabetes Care. 2019;42(3):416-426.

17. Kabadi UM. Cardiovascular outcome trials in type 2 diabetes: reliable or biased! World J Pharmaceutical Med Res. 2017;3(11):33-35.

18. The Diabetes Control and Complications Trial Research Group. The effect of intensive treatment of diabetes on the development and progression of long-term complications in insulin-dependent diabetes mellitus. $N$ Engl J Med. 1993;329(14):977-986

19. Epidemiology of diabetes interventions and complications (EDIC) research group. Epidemiology of diabetes interventions and complications (EDIC): design and implementation of a long-term follow-up of the diabetes control and complications trial cohort. Diabetes Care. 1999;22(1):99-111.

20. The diabetes control and complications trial/epidemiology of diabetes interventions and complications study at 30 years: Overview. Diabetes Care. 2014;37(1): 9-16.

21. Bebu I, Braffett BH, Orchard TJ. Mediation of the effect of glycemia on the risk of CVD outcomes in type 1 diabetes: the DCCT/EDIC study. Diabetes Care. 2019;42(7):1284-1289.

22. Roni Nielsen, Helene Nørrelund, Ulla Kampmann, e al. Effect of acute hyperglycemia on left ventricular contractile function in diabetic patients with and without heart failure: two randomized cross-over studies. PLoS One. 2013;8(1):e53247.

23. Kabadi UM. SGLT2 inhibitors: far too many cautions and alerts and limited efficacy. J Diabetes Metab Disord Control. 2016;3(5):90-94.

24. Kabadi UM. Marked weight loss, muscle wasting and fatigue on administration of empagliflozin in a subject with type 2 diabetes. $J$ Adv Med Med Res. 2017;21(5):1-7.

25. Kabadi UM. SGLT2 inhibitors and ketoacidosis: epidemiology and pathophysiology. J Diabetes Islet Biol. 2018;3:1-4. 